\title{
Maxicircle architecture and evolutionary insights into Trypanosoma
}

\section{cruzi complex}

Luisa Berná ${ }^{1,2}$, Gonzalo Greif ${ }^{1}$, Sebastián Pita1,3, Paula Faral-Tello¹, Florencia Díaz-Viraqué1, Rita De Cássia Moreira De Souza4 ${ }^{4}$ Gustavo Adolfo Vallejo55, Fernando Alvarez-Valin², Carlos Robello ${ }^{1,6}$

${ }^{1}$ Laboratorio de Interacciones Hospedero-Patógeno, Unidad de Biología Molecular, Institut Pasteur de Montevideo. Uruguay.

${ }^{2}$ Sección Biomatemática - Unidad de Genómica Evolutiva, Facultad de Ciencias, Universidad de la República. Uruguay

${ }^{3}$ Sección Genética, Facultad de Ciencias, Universidad de la República. Uruguay.

${ }^{4}$ Grupo Triatomíneos, Instituto René Rachou, Fundação Oswaldo Cruz - Fiocruz, Belo Horizonte, Minas Gerais, Brazil

${ }^{5}$ Laboratorio de investigaciones en Parasitología Tropical (LIPT). Facultad de Ciencias. Universidad del Tolima, Colombia

${ }^{6}$ Departamento de Bioquímica, Facultad de Medicina, Universidad de la República. Uruguay.

Keywords: Maxicircles; Trypanosoma cruzi, kDNA, DTUs, T. cruzi phylogeny, kinetoplast, mitochondrial DNA 


\section{Abstract}

We sequenced maxicircles from $T$. cruzi strains representative of the species evolutionary diversity by using long-read sequencing, which allowed us to uncollapse their repetitive regions, finding that their real lengths range from 35 to $50 \mathrm{~kb}$. T. cruzi maxicircles have a common architecture composed of four regions: coding region (CR), AT-rich region, short (SR) and long repeats (LR). Distribution of genes, both in order and in strand orientation are conserved, being the main differences the presence of deletions affecting genes coding for NADH dehydrogenase subunits, reinforcing biochemical findings that indicate that complex I is not functional in $T$. cruzi. Moreover, the presence of complete minicircles into maxicircles of some strains lead us to think about the origin of minicircles. Finally, a careful phylogenetic analysis was conducted using coding regions of maxicircles from up to 29 strains, and 1023 single copy nuclear genes from all of the DTUs, clearly establishing that taxonomically T. cruzi is a complex of species composed by group 1 that contains clades A, B and D, and group 2 containing clade $\mathrm{C}$. No significant differences were found in hybrid strains that justify the existence of TcV and Tc VI as separate clades: our results indicate that a unique event of hybridization between Tcll and Tclll occurred. Three variants of maxicircles exist in T. cruzi: $a, b$ and $c$, in correspondence with clades $A, B$, and $C$ from mitochondrial phylogenies. While $A$ and $C$ carry maxicircles a and $c$ respectively, both clades $B$ and D carry b maxicircle variant; hybrid strains also carry the b- variant. We then propose a new nomenclature that is self-descriptive and makes use of both the phylogenetic relationships and the maxicircle variants present in $T$. cruzi. 


\section{Introduction}

As their name states, kinetoplastids are characterized by harboring the kinetoplast, a single branched mitochondria with an intricate organization of its own DNA, called kinetoplast DNA (kDNA). kDNA is a complex network of thousands of catenated circular DNAs of two types, the minicircles and the maxicircles $(1,2)$. Maxicircles are equivalent to the mitochondrial genome of other eukaryotes, whereas minicircles are much shorter (seldom longer than $2 \mathrm{~kb}$ ) and encode the guide RNAs (gRNAs) needed for editing most of the maxicircle transcripts $(1,2)$. During the editing, insertions and deletions of uridine residues at specific sites occur on target ARNs posttranscriptionally in order to obtain mature transcripts (3-5). The complete genome of Trypanosoma cruzi maxicircles was first published in 2006 (6), in a comparative analyses of CLBrener and Esmeraldo strains, whose maxicircle sizes were estimated to be of $22 \mathrm{~Kb}$ and $28 \mathrm{~Kb}$ respectively, but a collapsed zone of repetitive sequences prevented their complete assembly. Recently, on a deep analysis of maxicircle divergent regions, Gerasimov et al. were able to "decompress" repetitive regions in trypanosomatids by using long reads (7). Although similar at the taxonomic and structural level, trypanosomatids have very different lifestyles. In vertebrates, while Leishmania spp. infects cells belonging to the mononuclear phagocytic system, T. brucei remains extracellular, and $T$. cruzi is able to invade almost any kind of nucleated cells (8). Their phlebotomes vectors for transmission, Tse-Tse flies and triatomines respectively, are evolutionarily very distant, so even intuitively one can anticipate that these parasites will use very different biological strategies to survive. In that context, species and genus are clearly defined in Leishmania spp., for which a good correlation between species and clinical manifestations exists (9), and similarly, T. brucei taxonomy is well defined in those causing sleeping sickness in humans (T. b. gambiense and T. b. rhodesiense) (9). However, the case of $T$. cruzi speciation 
remains still unclear. A few decades ago, two main clades of $T$. cruzi were described (I and II) based on biological and biochemical criteria, as well as molecular biology methods $(10,11)$. Subsequently, the use of sequences from genes and intergenic regions allowed the construction of gene phylogenies clearly showing that $T$. cruzi is composed of three major lineages which were called A, B and C, and that the distances between them were as large as that between $L$. major and L. mexicana (12). This analysis introduced the concept of $T$. cruzi as a "species complex" instead of a single species. The three main clades were later confirmed by Machado and Ayala (13) that also described a fourth clade (D), and the presence of hybrid B/C strains. Afterwards, several analyses reinforced the view that the evolutionary relationships among $T$. cruzi "strains" cannot be reduced to a two groups scenario, proposing more complex relationships. This was accompanied by a change in the nomenclature, between letters and Roman numerals: the initial groups I and II were reclassified as I and Ila to Ile (14), and later on the six groups were numbered Tcl to TcVI, and called "discrete typing units" (DTUs, $(15,16))$, where TcV and TcVI correspond to the hybrid lineages derived from haplotypes Tcll (C) and Tclll (B). In addition it was postulated that bat-derived T. cruzi constitutes a seventh DTU (17). Although in the last decade the "ABCD" denomination fell into oblivion, probably due to the high number of descriptive papers attempting to correlate DTUs to infected hosts, geographical areas, clinical manifestations, among others, the presence of three main evolutionary lineages was recently "rediscovered" in the form of a third musketeer (18), showing very similar results to those described ten years before $(12,13)$.

In this work we obtained high quality assemblies of maxicircle genomes from the six DTUs of $T$. cruzi, including the elusive "dark matter" of repetitive regions, which allowed us in the first place 
to determine the precise architecture of maxicircles and its variations, and ensure a better knowledge and understanding of the evolution of $T$. cruzi.

\section{Results}

\subsection{Complete maxicircle genomes of the six DTUs}

For maxicircle genome analysis six strains were selected, one from each DTU: Dm28c (Tcl), Y (Tcll), MT3663 (TcIII), JoseJulio (TcIV), BolFc10A (TcV) and TCC (TcVI).The DTU assignments of each of these strains were confirmed by multilocus PCR targeting the intergenic region of spliced leader genes (SL-IR), the 24Sa subunit ribosomal DNA (rDNA 24Sa) and the A10 fragments, as described by Burgos et al.(19) (Figure S1). Using long reads from PacBio and Nanopore and post-corrected with Illumina reads, each maxicircle was assembled into a single circular contig, their sizes ranging from $\sim 35 \mathrm{~Kb}$ to $\sim 50 \mathrm{~Kb}$ (Table 1 ). Long read sequencing allowed us to determine that the maxicircles sequences of the six strains analyzed shared organization and compositional structure. We could identify four clearly defined regions conserved among them: the coding region $(C R)$, two repetitive regions -the short (SR) and the long (LR) repeatsand an AT-rich region $(<1 \mathrm{~kb})$ located between the coding region and the short repeat cluster (Figure 1 and Figure 2A). 
Table 1. Statistics of assembled maxicircles. Length of coding region, AT rich region, short and long repeat region are reported for each strain. $\left(^{*}\right)$ base pairs.

\begin{tabular}{|c|c|c|c|c|c|}
\hline $\begin{array}{l}\text { Strain } \\
\text { (DTU) }\end{array}$ & $\begin{array}{l}\text { Length* } \\
\text { (\%GC) }\end{array}$ & $\begin{array}{l}\text { Coding region* } \\
\text { (\%GC/\%length) }\end{array}$ & $\begin{array}{l}\text { Short repeat* } \\
\text { (\%GC/\%length) }\end{array}$ & $\begin{array}{l}\text { Long repeat }^{*} \\
\text { (\%GC/\%length) }\end{array}$ & $\begin{array}{l}\text { AT rich } \\
\text { region* (\%GC) }\end{array}$ \\
\hline $\begin{array}{l}\text { Dm28c } \\
(\mathrm{Tcl})\end{array}$ & $50478(24,1)$ & $15359(25,4 / 30,4)$ & $4163(21,1 / 8,2)$ & $30321(23,9 / 60)$ & $635(17,3)$ \\
\hline Y (Tcll) & $38789(22,5)$ & $13852(24,9 / 35,7)$ & $4913(20,1 / 12,7)$ & $19887(21,3 / 51.2)$ & $137(23,9)$ \\
\hline $\begin{array}{l}\text { MT3663 } \\
\text { (TcIII) }\end{array}$ & $44186(25,7)$ & $15293(26,2 / 34,6)$ & $5067(20,6 / 11,5)$ & $22830(27,0 / 51.7)$ & $996(17,1)$ \\
\hline $\begin{array}{l}\text { JoseJulio } \\
\text { (TcIV) }\end{array}$ & $44279(25,8)$ & $15263(26,1 / 34,5)$ & $5196(20,7 / 11,7)$ & $22878(27,0 / 41.2)$ & $942(17,4)$ \\
\hline $\begin{array}{l}\text { BolFc10A } \\
(\mathrm{TcV})\end{array}$ & $34804(26,8)$ & $17536(27,7 / 50,4)$ & $2135(21,2 / 6,1)$ & $14324(27,1 / 41.2)$ & $809(17,5)$ \\
\hline TCC (TcVI) & $42479(25,6)$ & $15339(26,1 / 36,1)$ & $6797(20,2 / 16)$ & $19343(27,3 / 45)$ & $1000(25,3)$ \\
\hline
\end{tabular}

\subsection{Architecture of maxicircle genome}

Maxicircle comparison clearly indicates that the four regions previously mentioned are conserved in the different lineages of $T$. cruzi (Figure S2); however, whereas lengths of coding regions are relatively similar, significant differences were found among DTUs in the short (from $\sim 2.1 \mathrm{~Kb}$ to 
$\sim 6.8 \mathrm{~Kb}$ ) and long (from $\sim 14.3 \mathrm{~Kb}$ to $\sim 30.3 \mathrm{~Kb}$ ) repeats, as well as in the AT-rich region (from $\sim 0,1 \mathrm{~Kb}$ to $\sim 1 \mathrm{~Kb})$, as summarized in Table 1 . Nucleotide composition and skews clearly separate the four regions, and each one has a peculiar base composition (Figure $2 \mathrm{~A}$ and Figure S2). In the coding regions, nucleotide composition always correlates with gene orientation (+ or - strand) and the editing pattern (Figure 2A and Figure S3); for example GC-skew (and reciprocally AT-skew) is lower in absolute number for the non-edited genes $n d 2, n d 1, \mathrm{col}, n d 4$ and $n d 5$, changing from negative to positive depending on its orientation $(n d 2, n d 1, c o l$ in the negative strand; $n d 4, n d 5$ in the positive strand; Figure S3). Repetitive nature and different structure and composition of the SR and LR can be clearly visualized in the dotplots (Figure 3 and Figure S4). On the one hand, despite the fact that the unit of repetition of the short repeat is not apparent, we found a consensus sequence of $67 \mathrm{bp}$ as a part of a longer repeat, with high AT content $(77 \%)$ that is found in all but $Y$ strain, with different levels of identity ranging from $75 \%$ to $100 \%$ (Table S1). On the other hand, the long repeat also presents low identity among its monomers but notably, each one is delimited by a highly conserved element of $39 \mathrm{bp}$, which is present in all maxicircles in $\sim 1$ $3 \mathrm{~kb}$ intervals depending on the strain, which is palindromic and consequently has the possibility to form cruciform structures (Figure 2C). By using maxicircles coding regions from $T$. brucei, $L$. donovani, T. vivax and T. congolense a similar pattern was found (Figure S5).

\subsection{Insertions, deletions and gene truncations}

Insertions and deletions were found in the maxicircle coding regions of BolFc10A and $Y$ strains, respectively (Figure $2 \mathrm{~B}$ and $2 \mathrm{D}$ ). These variations are not due to artifacts in the assembly since many reads completely pass through insertions and deletions, with high coverage, ranging from 30x to 110x (Figure S6 A). The Y strain (TcIl) presents two deletions of 452 and $1071 \mathrm{bp}$, the first disrupting the $n d 7$ gene, and the second provoques the 5 ' deletion of $n d 2$ (110 bp), the complete 
elimination of $c r 3$, and $3^{\prime}$ deletion of $n d 1$ (780 bp), from which only remain the first 5' 167 nucleotides (Figure 2B). This insertion was not present in the Tcll strains Berenice and Esmeraldo, however the same previously reported 236 bp deletion in Esmeraldo that disrupts nd4 (6) is present in Berenice but not in $\mathrm{Y}$ (Figure S7). On the other hand, BolFc10A strain (TcV) has two insertions of 1408 bp and 1017 bp length, separated by 893 bp (Figure 2B, and 2D). Sequence analysis of both insertions shows that they belong to minicircle sequences, the first one of $1408 \mathrm{bp}$ corresponds to an entire minicircle including the four conserved characteristic regions (Figure 2D), and the 1017 bp corresponds to a partial minicircle sequence, maintaining homology only at the conserved regions (Figure 2D). Although the insertions correspond to two different minicircles, in both cases they carry the same gRNA for nd3 gene (Figure S8). The minicircle conserved regions can be also visualized in the dotplots as a third repetitive region in TcV (Figure 3), and exhibit very high coverage of mapped reads, indicating that these sequences are probably present in the minicircle repertoire (Figure S6B). The first insertion disrupts the nd4 gene (position 632), the second is located in the intergenic region between nd4 and nd3, and a third one interrupts $n d 2$ (Figure 2B).

\subsection{Phylogenetic analysis of $T$. cruzi maxicircles}

The phylogenetic analysis of the six DTUs by using the complete coding regions of maxicircles identifies three clearly delimited clades - A, B and C -, with an identical structure to that previously described (12), where A corresponds to Tcl, B to TcllI-VI-V-VI, and C to Tcll (Figure 4); B forms a compact group, whereas A and C present greater distances between them and to TcllI-TcVI with values of $\sim 7$ and $\sim 10$ respectively (Figure 4 ). In agreement with these data, similar results were recently observed $(20,21)$. We then sequenced (Illumina) more strains (Tables S2) with low coverage, but sufficient to obtain the entire coding regions, and an identical 
clusterization structure was found (Figure S9A). In this last experiment three TcBat strains were included and it is clearly determined that they belong to clade A. From another perspective we can establish that in T. cruzi exist three maxicircles variants: a, b and c, and their differences not only depend on their coding regions: in the dotplots it can be visualized that they have differences in their patterns in the LR regions (Figure 3 and S4). It is worth mentioning that the recently PacBio sequenced TcV strain Bug2148 (22), falls into clade A, closely related to Sylvio strain (Figure S9B). This unexpected phylogenetic location is also supported by a nuclear single-copy genes phylogeny (see below and Figure S10) indicating that the strain named Bug2148 does probably correspond to Sylvio $\mathrm{X} 10 \mathrm{Cl} 1$, and that is why it was not included in our analyzes. Recent phylogenetic analysis are in line with this observation $(20,21)$.

\subsection{Mitochondrial vs. Nuclear phylogenies}

To get a whole picture of the evolutionary history and phylogenetic relationships of $T$. cruzi, a robust phylogeny was performed by identifying those nuclear genes having a unique copy in all of the DTUs. In addition to the strains used along this work, we included the available genomes from Sylvio (Tcl) (23) CLBrener (TcVI/haplotypes Tcll and TcllI) (24,25), 231 (TcllI) (26), AM64

(TcIV) (27), plus T. cruzi marinkellei as an outgroup, obtaining a list of 85 single-copy genes

(Table S3). It should be noted that although there are many unique genes, the different completeness of the genomes used results in the recovery of only a set of 85 unique conserved genes. The ML tree shown in Figure 5 (left), allows to identify two main clades, one early branching clade (Group 1) composed by C strains (Tcll), and another (Group 2) composed by A, B and D strains (Tcl, Tclll and TcIV respectively), being A, B, C and D all monophyletic. Every branching event is well supported by bootstrap values $>0.9$. When we excluded hybrid strains, 1023 (instead of 85, Table S4) single-copy nuclear genes were identified, and the phylogenetic 
ML tree obtained shows the same topology with the four clades (Figure S10). To compare nuclear and kDNA phylogenies, we used the same strains on the analyses with the addition of the already published Tc Esmeraldo strain kDNA sequence (6), to compare it with CLBrenerEsmeraldo like nuclear haplotype. The ML tree generated using all coding genes from the maxicircles is presented in Figure 5. Clades $A$ and $C$ show a clear correspondence between mitochondrial and nuclear clades, whereas the both $B$ and D nuclear clades correspond with the mitochondrial clade B; every branching event is well supported by bootstrap values higher than 0.9 .

\section{Discussion}

The kinetoplast has been widely studied in trypanosomatids due to their distinctive properties, making it an attractive target for therapies for Chagas disease, leishmaniasis and sleeping sickness. It also constitutes a valuable phylogenetic marker for the reconstruction of trypanosomatids evolutionary story (reviewed by Kaufer et al (28)). In this work, by using a combination of short (Illumina) and long (PacBio and Nanopore) read DNA sequencing, a total of six T. cruzi maxicircles were sequenced and assembled. This strategy allowed us to determine their real length and structure. We found that in all cases their lengths were previously underestimated, mainly due to the presence of two repetitive regions SR and LR (Table 1 and Figure 1), that collapsed during the assembly using first and second generation sequencing methods . The length of $T$. cruzi maxicircles ranges from $34,804 \mathrm{bp}$ to $50,478 \mathrm{bp}$, which coincides with the variability described recently in other trypanosomatids, where also the main source of size differences is at expenses of repeats (7). It is very important to highlight that these dimensions are compatible with reports from 3-4 decades ago and later ignored, probably due to the overvaluation of "modern" methods, as usually happens with fashion. In an elegant work, Leon et 
al. (29) extracted kDNA from the $Y$ strain, obtaining high degrees of purity from Nal gradients, and studied them by restriction patterns and electron microscopy, concluding that the approximate molecular weight was around $26 \times 10^{6} \mathrm{Da}$. If we consider that the molecular weight average of a single base pair is $650 \mathrm{Da}$, the deduced length from that publication is $40 \mathrm{kDa}$, and our results on $\mathrm{Y}$ strain agree with that pioneer work. To those authors our recognition.

We found that the overall structure of T. cruzi maxicircles is conserved among DTUs, and consists in four regions: a) coding region (CR); b) AT-rich region (ATr); c) short repeat (SR); d) long repeat (LR), each one with a particular nucleotide composition (Table 1 and Figures 1 and 2). Regarding the AT-rich region (AT content $83 \%$ ), its irruption indicates the end of the coding region, and its length ranges from 137 to $1000 \mathrm{bp}$. The changes in composition, as well as the AT-rich regions were associated with the mitochondrial replication origin $(29,30)$; in trypanosomatids, the origin of replication has been identified at different positions flanking the coding region either upstream ( $T$. brucei) or downstream (C. fasciculata), but in both cases related to repetitive regions(31); knowing if they are located on the short or the long repeat can provide clues as which of those regions contain replication origins. Concerning the short and long repeats, they exhibit vestigial monomers with low identity among them. Previously, similar structures have been described for $T$. cruzi as P5 and P12 elements, according to their proximity to the ND5 and 12Sgenes (7). Our analysis revealed that the short repeats show similar composition among DTUs, and cover between $6.1 \%$ to $16 \%$ of maxicircle length (Table 1 ). A conserved region of $65 \mathrm{bp}$ was identified in these repeats (Table S1). Indeed, it was not possible to identify it on $Y$ strain, although it is present in Esmeraldo and Berenice Tcll strains. The long repeat covers, depending on the strain, between $41.2 \%$ to $60 \%$ of the total maxicircle length (Table 1). It does not show high sequence conservation among the different groups, but presents 
an inverted repeat composed by a conserved palindromic sequence of 39 bp (Figure 2C). This palindrome has been previously found in the first maxicircle genome reported, although only two copies were identified at that time (6). Here we determined that it constitutes a hallmark of $T$. cruzi maxicircles, since it is present in all of them in at least eight copies defining the repetition unit of long repeats (Figura 2C). Palindromic structures were found in most mtDNAs studied (33) in chloroplasts and proteobacteria genomes $(34,35)$, but their function is not known. In eukaryotes they have been associated with a diversity of functions like replication origins, and as targets for many architectural and regulatory proteins, such as histones $\mathrm{H} 1$ and $\mathrm{H} 5$, topoisomerase II $\beta$, HMG proteins, p53, among others (36). Although the function of the $39 \mathrm{bp}$ palindrome remains to be elucidated, its high degree of conservation and periodicity can explain the ability of maxicircles to self-associate, even after elimination of RNA and proteins (37), and could be critical in kDNA structure. Taken together these observations lead us to propose this new nomenclature (CR, ATr, SR and LR) to describe maxicircles architecture, instead of the current denomination of conserved and divergent regions (CR and DR). We recently found in Trypanosoma vivax the same short and long repeat structure, is present in both in American and African strains (38), in addition to the dotplots obtained in this work for T. brucei, L. donovani, T. vivax and $T$. congolense (Figure S5) strongly suggest this is a common pattern and hence, their functional roles deserve to be investigated.

The coding regions, reported to conserve the gene order among trypanosomatids, include genes encoding for members of the respiratory chain nd (subunits 1-5; 7-9), co (subunits I-III), cyt b, and ATPase, and the open reading frames of unknown function murf and $c r$. The $T$. cruzi complex not only conserves the order of genes among DTUs but also the strand location (Figure 2B). As was previously observed (6) GC or AT skews are good predictors of location of protein coding genes: 
positive GC-skew and AT-skew values represent genes in the plus and minus strand respectively, with the exception of $c r$ genes (in agreement with their base composition:"c-rich genes"): cr3 is surrounded by nd2 and nd3, and no changes in AT skew are observed, and cr4 exhibits the same pattern as col, located in the opposite strand (Figure 2A and Figure S3). Despite the high degree of conservation in the coding region, insertions and deletions were detected (Figure 2B). These variations may represent events that occurred exclusively in the particular sequenced strain or can they be common to a given lineage. Either way, this illustrates the degree of variability of $T$. cruzi maxicircles. Two deletions were found in $\mathrm{Y}$ (Tcll), a $1071 \mathrm{bp}$ deletion located in the intergenic region between $n d 1$ and $n d 2$, with the consequent elimination of $c r 3$, and a 452 bp deletion disrupting $n d 7$ (Figure 2B). It is worth noting that the same $n d 7$ truncation was already found in T. cruzi strains isolated from asymptomatic patients (39), where the authors analyze by PCR the nd7 truncation, showing that it is not a feature of Tcll. Although this deletion is not present neither in Esmeraldo nor in Berenice, we found that both strains present a similar deletion affecting nd4 gene. In addition, Berenice strains present two further deletions affecting this gene (Figure S7) similar to that described by Westemberg et al. (6). In the case of TcV, BolFc10A presents an insertion that interrupts the $n d 4$ gene, whereas a second one falls on an intergenic region (Figure 2B). The finding of deletions always affecting mitochondrial genes encoding NADH dehydrogenase subunits, raises the question about the existence of a functional complex I in T. cruzi (40) in which, as with most eukaryotes, respiration occurs via the electron transport chain (ETC) coupled to ATP synthesis (41). Decades ago it was clearly demonstrated that the main source of electrons in T. cruzi ETC is succinate instead of NADH: no inhibition of respiration was found after the addition of inhibitors of complex I, whereas both motility and respiration of epimastigotes were inhibited by malonate, a competitive inhibitor of the 
mitochondrial succinate dehydrogenase (42). In view of our findings, it would be relevant to reevaluate cellular respiration in different strains with and without deletions of $n d$ genes, to draw conclusions about the presence of a functional complex I in $T$. cruzi. In fact, a possibility is that the integrity and functionality of complex I would depend on the strain.

The two major insertions of TcV correspond either to a complete minicircle (1408 bp) or to an incomplete one (1017 bp), the former containing the four CSBs (Figure 2D and S8). It is remarkable that the presence of a complete -and even an incomplete- minicircle inserted in a maxicircle has not been reported before, and its presence could be a consequence of a horizontal transfer, from mini to maxicircles, since it has been documented the relatively high inter-minicircle recombination rate (43). The presence of gRNA genes in maxicircles was reported in different trypanosomatids. In fact, initially it was postulated that gRNAs were encoded in maxicircles due to their presence in maxicircles of L. tarentolae (44), C. fasciculata (45), and T. brucei, where gMURFII-2 was found to be transcribed as an individual transcription unit from maxicircle (46), similar to what happens in minicircles. In the case reported here, also the conserved regions are present, giving their gRNAs a genomic context for transcription; remarkably both sequences carry different gRNAs but directed to the same nd3 gene (Figure S8). The biological significance of these insertions is not clear, and at this point we are tempted to speculate with the possibility of the inverse flux: maxicircles can constitute seeds of minicircles, and what we "captured" was a snapshot of a dynamic process, which will probably end with the functional elimination of the "inserted" minicircles. In fact a "free" version of the larger minicircle is also present, as indicated by the fact that sequencing depth is massively higher in the segment of the maxicicircle containing the insertion, shown in Figure S6B. In any case, there is still much to know about the origin and evolution of this fascinating process. 
Three variants of maxicircles were detected: $a, b$ and $c$, that correspond to the clades $A, B$, and $C$ (Figure 4 and S9A). The non-hybrid Tcl, Tcll and Tclll-IV bear the maxicircles a, c and b respectively, whereas both the hybrid strains TcV and TcVI carry the b-maxicircle (lowercases are used to distinguish variants from clades). These three main clades exactly match with those previously proposed by us more than 20 years ago (12) and, since in that work nuclear sequences were used, the $A B C$ clustering pattern would not be due to a bias for using maxicircle sequences. To evaluate this hypothesis a careful phylogenetic analysis was performed, using more than a thousand single-copy nuclear genes, confirming a correspondence between nuclear and mitochondrial trees (Figure 5), with the addition of a fourth D clade (Tc IV). This new clade is closely related to $A$ and $B$ clades, and carries the b-maxicircle. Clade $D$ was initially described by Ayala and Machado (2001) who, using the mitochondrial CYb, and the nuclear rRNA promoter genes, obtained three (A-C) or four (A-D) clades respectively, clade D corresponding to TclV. It is worth wondering: what is the origin of clade D? Until now it has been a headache to place this clade (TclV) in T. cruzi phylogenies. It is clear that A, B and D share a more recent common ancestor (compared to $\mathrm{C}$ ), but why does $\mathrm{D}$ carry b-maxicircles? The explanation that $\mathrm{B}$ and $\mathrm{D}$ diverged from an ancestor already containing the b-maxicircle is highly unlikely, considering the results revealed by nuclear trees (Figure 5), where A, B and D are monophyletic, and two kind of maxicircles are present ( $a$ and $b)$. A second hypothesis to account for this discrepancy is that mitochondrial transfer (introgression) occurred between B and D (13,47-50). The proponents of this interpretation suggest that D strain would have acted as the donor $(48,49)$. There are two points of concern about this introgression hypothesis. First, it appears unlikely the occurrence of an event involving exclusively mitochondrial "passage" without nuclear mixture and subsequent recombination. Although previous results are compatible with this view (reviewed in (49)), they 
are based on very limited datasets of nuclear genetic material. To tackle this contradictory situation only a deep comparative genome analysis between B and D genomes is necessary; if hybridization occurred between B and D clades, vestigial mosaic genomes should be found. The second aspect where the results presented herein are at odds with previous proposals, involves the direction of the genetic transfer. In effect, the phylogenetic analysis presented here suggests that in the case of introgression, the direction was from B to D and not the other way around as suggested before. In our view, if D (TclV, JoseJulio, AM64) was the donor, then its placement in the tree should be as the earliest branching group in the B clade of the mitochondrial tree (Figures 5 and S9). This is why we named $b$ and not $d$ this maxicircle variant.

At this point, it is necessary to revisit the classification and nomenclature of DTUs. Although it constitutes a very useful tool to genetically differentiate the members of the T. cruzi complex, we visualize two main concerns. First, revisiting the origin of nomenclature it can be observed that the initial classification into groups I and II does not correspond to the phylogeny of T. cruzi (B and $D$ are separated from A). This can best be seen after the subdivision into I and Ila-e, (which is at the basis of the current classification in DTUs I to VI respectively): $A$ (Tc I) became separated from B and D. Second, in this classification both hybrids and non-hybrids clones are located at the same hierarchical level and hence, this nomenclature lacks information in this regard. Additionally, no information about the maxicircle variant is given. Based on the drawbacks just mentioned, we propose to adopt the nomenclature shown in Figure 6: T. cruzi constitutes a complex composed of two main groups, 1 and 2, to differentiate them from I and II (since the latter lack correspondence with phylogenetic distances among clades), and four main lineages (clades): three belonging to group $1(\mathrm{Aa}, \mathrm{Bb}, \mathrm{Db})$, and the fourth belonging to Group $2(\mathrm{Cc})$; in addition, there are hybrid strains named $\mathrm{BCb}$. Uppercase letters stand for nuclear genomes and 
lowercase letters indicate the maxicircle variant. This understanding and nomenclature can contribute to "put an order in the house", and focus the analysis of each clade to delve into their biological features. For example, in clade A we found: I) that at least two subgroups exist, one of them represented by Dm28c and Sylvio (Figures 5, S9 and S10) and the second one by the socalled TcBat strains. Indeed TcBat strains used here clearly belong to clade A and carry the amaxicircle (Figure S9), therefore they all can be unambiguously classified as Aa. It is worth stressing that in this sense this new nomenclature avoids the temptation to propose more and more DTUs as new relatively non-divergent variants are discovered. A very relevant point is the case of hybrid strains. Our results indicate that a unique event of hybridization occurred in $T$. cruzi and hence, TcV and TcVI cannot be separated at the genomic level, and this was the reason by which we grouped them as $\mathrm{BCb}$. Analysis of a greater number of genomes will allow confirming this result. Finally, to shed light on the origin of the close relationship between B and $D$, including the fact that they share the same maxicircle, whole genome analysis will help determine how hybridization and/or introgression events have occurred.

\section{Funding}

This work was supported by: Research Council United Kingdom Grand Challenges Research Funder under grant agreement 'A Global Network for Neglected Tropical Diseases' grant number MR/P027989/1; Agencia Nacional de Investigación e Innovación(UY) DCl-ALA/2011/023-502, ‘Contrato de apoyo a las políticas de innovación y cohesión territorial', Fondo para la Convergencia Estructural del Mercado Común del Sur(FOCEM) 03/1; Fundacão de Amparo à Pesquisa do Estado de Minas Gerais (CBBAUC 00030-15). FDV has a doctoral fellowship from Agencia Nacional de Investigación e Innovación (ANII, Uruguay). LB, GG, FAV and CR are members of the Sistema Nacional de Investigadores (ANII, Uruguay). 
bioRxiv preprint doi: https://doi.org/10.1101/2021.05.11.443566; this version posted May 11, 2021. The copyright holder for this preprint (which

was not certified by peer review) is the author/funder, who has granted bioRxiv a license to display the preprint in perpetuity. It is made available under aCC-BY 4.0 International license. 


\section{Material and Methods}

\section{T. cruzi strains and DNA extraction}

DNA was isolated by phenol extraction as described (51), and the integrity was checked by $1 \%$ agarose gel electrophoresis. The following strains were sequenced by Illumina technology: AP3-1, Colombiana, SC16, Sylvio X10 cl1 and Ort8-1 (Tcl); ChaQ8-1, Cha_Q11-2 and ChaQ8-2 (Tcl Bat); Y, PNM, Berenice, Esmeraldo cl3 and IVV cl4 (Tcll); MT3663, Merejo do Anjico and 231 (TcllI); JoseJulio and AM64 (TcIV); BolFc10A (TcV); CLBrener (TcVI). The following strains were also sequenced by Nanopore: Y, MT3663, JoseJulio and BolFc10A. Finally, sequences from Dm28c, TCC, Bug21448, CLBrener Esmeraldo-like, CLBrener Non Esmeraldo-Like and Tc. marinkellei were retrieved from TriTrypDB and NCBI databases.

\section{Discrete Typing Unit (DTU) determination}

For DTU typing the following PCR products were amplified and sequenced as described in (19): the intergenic region of spliced leader genes (SL-IR), the 24Sa subunit ribosomal DNA (rDNA 24Sa) and the A10 fragment. Size determination of PCR products was done onto $5 \%$ MetaPhor $®$ agarose gels.

\section{Library construction and sequencing}

PacBio Sequencing was performed in the sequencing service of City of Hope (USA) using $10 \mu \mathrm{g}$ of $T$. cruzi $\mathrm{Y}$ strain. Nanopore Sequencing was performed in our laboratory. Briefly, genomic DNA was fragmented to $20 \mathrm{~kb}$ using g-Tubes (Covaris, USA), according to manufacturer instructions and libraries were prepared with the kitEXP-NBD103/SQK-LSK108 (Nanopore, England) according to (52), starting from $1 \mu \mathrm{g}$ of total fragmented genomic DNA. Libraries were run for 20 hours in R9.4 FlowCells (FLOMIN106, Nanopore, England). Whole-genome Illumina sequencing libraries were performed as previously described in Pita el at. (53) using Nextera XT (Illumina). Paired-end reads were sequenced on the MiSeq platform ( 2 x 150 cycles $)$. 


\section{Assembly and annotation of maxicircle genomes}

Long reads: FAST5 reads containing raw Nanopore signal were basecalled in real time using MinKNOW Nanopore software, and locally using Guppy toolkit (Oxford Nanopore Technologies). Porechop (https://github.com/rrwick/) was used to demultiplexing reads.

PacBio reads were assembled with HGAP v3 as described in (54) and Nanopore reads were assembled with Canu v1.8 (55). Afterwards, backmapping Illumina reads with bwa (56), and using samtools for sam manipulation (57) and Pilon (58) were employed to polish the assembly. Contigs containing maxicircle sequences were recovered from the assembly using Blast (59) with previous $T$. cruzi maxicircle assemblies (6) used as subject.

Illumina reads: Reads belonging to kDNA were identified aligning all reads to already available kDNAs using BWA mem (56) with default parameters, and extracted with samtool (31) and bedtools (60). Extracted maxicircle's reads were assembled using SPAdes version 3.8.0 (61) with default parameters. Scaffolds containing maxicircle sequences corresponding to the coding region were recovered from assembly using Blast (59) and controlled by base composition.

Annotation and Data handling: Maxicircles annotation was performed manually using Blast (59). Coverage analyses were performed mapping illumina and long reads with BWA (56) and Minimap2 (62), respectively, and obtaining the amount of mapped reads using mpileup samtools (57). R version 4.0.2 (63) with seqinr package, were used to obtain GC, GC and AT skews, and coverage plots. IGV (64) was used for alignment visualizations. Comparative analyses and visualization of coding regions were performed using ACT (65). Circos (66) was used to create circular plots. Dotplots were performed using YASS web server (67).

\section{kDNA genes phylogenetic analysis}


kDNAs obtained by illumina sequencing were analyzed in order to present at least 14 coding genes. A total of 17 strains fulfilled this requirement and were further processed. The entire coding region of the kDNAs were aligned using MAFFT v7.471 (68) with the linsi method and visualized with JalView (69). The alignment was trimmed using trimAl (70) with option -gt 0.8. ML tree was generated by IQ-TREE (71) using GTR+F+G4 including 1000 bootstrap pseudoreplicates and visualized with FigTree (http://tree.bio.ed.ac.uk/software/figtree/).

\section{Nuclear vs kDNA genes phylogenetic analysis}

Single copy genes were retrieved using a pipeline from Pita et al (in preparation). Briefly, a clustarization using MCL software (72) is performed on all annotated genes in the Dm28c strain genome (54) to get rid of all highly abundant gene families. Then each survivor is used as a blastN query on several strains genomes assemblies -T. cruzi Dm28c, Sylvio, Berenice, Y, 231, MT3663, Jose Julio, AM64, tcBolFc10A, TCC, CL Brener Esmeraldo and Non-Esmeraldo-like haplotypes and T. c. marinkellei B7. The search was restricted to those genes which present only one HSP with $90 \%$ of query coverage (-qcovhsp) in all genomes. A gap penalty was setted to avoid genes with deletions (-gapopen 3 -gapextend 2). Each dataset was aligned separately using MAFFT v7.310 (68), and then concatenated using bash scripts. Same strains were used to perform a ML phylogenetic tree using kDNA, with the addition of the Esmeraldo strain, to compare with the CLBrener Esmeraldo-like haplotype. For both datasets Maximum Likelihood (ML) tree was generated using RAxML (73), with a partition scheme taking each gene independently. Since the substitution model test for each gene runed separately indicated that HKY plus gamma distribution was the best fitted most times, two RAxML reuns were performed, one using GTRGAMMA and other using GTRGAMMA --HKY85. ModelGenerator v0.85 (74) software was employed to determine the best fitted model. The starting tree was found as the best-scoring ML tree using 20 randomized stepwise addition parsimony search (-p command). One hundred bootstrap pseudoreplicates were made (-b command) and then mapped onto the single most likely held tree topology (-f b command). In addition, to compare several approaches, ML trees were performed on both concatenated datasets with 
bioRxiv preprint doi: https://doi.org/10.1101/2021.05.11.443566; this version posted May 11, 2021. The copyright holder for this preprint (which

was not certified by peer review) is the author/funder, who has granted bioRxiv a license to display the preprint in perpetuity. It is made available under aCC-BY 4.0 International license.

IQ-TREE (71) and PhyML (75) softwares. The phylogenetic trees were visualized and edited using the $R$ package ggtree (76).

\section{Data Availability}

Maxicircle genome assemblies and annotations were deposited in NCBI including accession numbers:

Dm28c MW421590, Y MW421591, MT3663 MW567142, JoseJulio BolFc10A MW567141, MW421592,

TCC MW407947. Raw data were also deposited in NCBI BioProject PRJNA713613. 


\section{References}

1. Lukeš J, Lys Guilbride D, Votýpka J, Zíková A, Benne R, Englund PT. Kinetoplast DNA Network: Evolution of an Improbable Structure. Eukaryot Cell. 2002 Aug;1(4):495-502.

2. Lukeš J, Butenko A, Hashimi H, Maslov DA, Votýpka J, Yurchenko V. Trypanosomatids Are Much More than Just Trypanosomes: Clues from the Expanded Family Tree. Trends Parasitol. 2018;34(6):466-80.

3. Gott JM, Emeson RB. Functions and mechanisms of RNA editing. Annu Rev Genet. 2000;34:499_ 531.

4. Simpson L, Sbicego S, Aphasizhev R. Uridine insertion/deletion RNA editing in trypanosome mitochondria: a complex business. RNA N Y N. 2003 Mar;9(3):265-76.

5. Estévez AM, Simpson L. Uridine insertion/deletion RNA editing in trypanosome mitochondria--a review. Gene. 1999 Nov 29;240(2):247-60.

6. Westenberger SJ, Cerqueira GC, El-Sayed NM, Zingales B, Campbell DA, Sturm NR. Trypanosoma cruzi mitochondrial maxicircles display species- and strain-specific variation and a conserved element in the non-coding region. BMC Genomics. 2006 Mar 22;7:60.

7. Gerasimov ES, Zamyatnina KA, Matveeva NS, Rudenskaya YA, Kraeva N, Kolesnikov AA, et al. Common Structural Patterns in the Maxicircle Divergent Region of Trypanosomatidae. Pathogens [Internet]. 2020 Feb 5 [cited 2020 Dec 7];9(2). Available from: https://www.ncbi.nlm.nih.gov/pmc/articles/PMC7169413/

8. El-Sayed NM, Myler PJ, Blandin G, Berriman M, Crabtree J, Aggarwal G, et al. Comparative genomics of trypanosomatid parasitic protozoa. Science. 2005 Jul 15;309(5733):404-9.

9. Roberts LS, Janovy J, Schmidt GD. Gerald D. Schmidt \& Larry S. Roberts' Foundations of parasitology. Boston: McGraw-Hill; 2009.

10. Souto RP, Fernandes O, Macedo AM, Campbell DA, Zingales B. DNA markers define two major phylogenetic lineages of Trypanosoma cruzi. Mol Biochem Parasitol. 1996 Dec 20;83(2):141-52.

11. Tibayrenc M, Neubauer K, Barnabé C, Guerrini F, Skarecky D, Ayala FJ. Genetic characterization of six parasitic protozoa: parity between random-primer DNA typing and multilocus enzyme electrophoresis. Proc Natl Acad Sci U S A. 1993 Feb 15;90(4):1335-9.

12. Robello C, Gamarro F, Castanys S, Alvarez-Valin F. Evolutionary relationships in Trypanosoma cruzi: molecular phylogenetics supports the existence of a new major lineage of strains. Gene. 2000 Apr 4;246(1-2):331-8.

13. Machado CA, Ayala FJ. Nucleotide sequences provide evidence of genetic exchange among distantly related lineages of Trypanosoma cruzi. Proc Natl Acad Sci. 2001 Jun 19;98(13):7396-401.

14. Brisse S, Barnabé C, Tibayrenc M. Identification of six Trypanosoma cruzi phylogenetic lineages by random amplified polymorphic DNA and multilocus enzyme electrophoresis. Int J Parasitol. 2000 Jan;30(1):35-44.

15. Zingales B, Andrade SG, Briones MRS, Campbell DA, Chiari E, Fernandes O, et al. A new consensus for Trypanosoma cruzi intraspecific nomenclature: second revision meeting recommends Tcl to TcVI. Mem Inst Oswaldo Cruz. 2009 Nov;104(7):1051-4.

16. Zingales B, Miles MA, Campbell DA, Tibayrenc M, Macedo AM, Teixeira MMG, et al. The revised Trypanosoma cruzi subspecific nomenclature: rationale, epidemiological relevance and research applications. Infect Genet Evol J Mol Epidemiol Evol Genet Infect Dis. 2012 Mar;12(2):240-53.

17. Lima L, Espinosa-Álvarez O, Ortiz PA, Trejo-Varón JA, Carranza JC, Pinto CM, et al. Genetic diversity of Trypanosoma cruzi in bats, and multilocus phylogenetic and phylogeographical analyses 
supporting Tcbat as an independent DTU (discrete typing unit). Acta Trop. 2015 Nov;151:166-77.

18. Ruvalcaba-Trejo LI, Sturm NR. The Trypanosoma cruzi Sylvio X10 strain maxicircle sequence: the third musketeer. BMC Genomics. 2011 Jan 24;12:58.

19. Burgos JM, Altcheh J, Bisio M, Duffy T, Valadares HMS, Seidenstein ME, et al. Direct molecular profiling of minicircle signatures and lineages of Trypanosoma cruzi bloodstream populations causing congenital Chagas disease. Int J Parasitol. 2007 Oct;37(12):1319-27.

20. Majeau A, Murphy L, Herrera C, Dumonteil E. Assessing Trypanosoma cruzi Parasite Diversity through Comparative Genomics: Implications for Disease Epidemiology and Diagnostics. Pathog Basel Switz. 2021 Feb 16;10(2).

21. DeCuir J, Tu W, Dumonteil E, Herrera C. Sequence of Trypanosoma cruzi reference strain SC43 nuclear genome and kinetoplast maxicircle confirms a strong genetic structure among closely related parasite discrete typing units. Genome. 2020 Oct 21;1-7.

22. Callejas-Hernández F, Rastrojo A, Poveda C, Gironès N, Fresno M. Genomic assemblies of newly sequenced Trypanosoma cruzi strains reveal new genomic expansion and greater complexity. Sci Rep [Internet]. 2018 Oct 2 [cited 2020 Dec 8];8. Available from:

https://www.ncbi.nlm.nih.gov/pmc/articles/PMC6168536/

23. Franzén O, Ochaya S, Sherwood E, Lewis MD, Llewellyn MS, Miles MA, et al. Shotgun Sequencing Analysis of Trypanosoma cruzi I Sylvio X10/1 and Comparison with T. cruzi VI CL Brener. PLoS Negl Trop Dis [Internet]. 2011 Mar 8 [cited 2020 Dec 8];5(3). Available from:

https://www.ncbi.nlm.nih.gov/pmc/articles/PMC3050914/

24. El-Sayed NM, Myler PJ, Bartholomeu DC, Nilsson D, Aggarwal G, Tran A-N, et al. The genome sequence of Trypanosoma cruzi, etiologic agent of Chagas disease. Science. $2005 \mathrm{Jul}$ 15;309(5733):409-15.

25. Weatherly DB, Boehlke C, Tarleton RL. Chromosome level assembly of the hybrid Trypanosoma cruzi genome. BMC Genomics. 2009 Jun 1;10:255.

26. Baptista RP, Reis-Cunha JL, DeBarry JD, Chiari E, Kissinger JC, Bartholomeu DC, et al. Assembly of highly repetitive genomes using short reads: the genome of discrete typing unit III Trypanosoma cruzi strain 231. Microb Genomics [Internet]. 2018 Feb 14 [cited 2020 Dec 8];4(4). Available from: https://www.ncbi.nlm.nih.gov/pmc/articles/PMC5989580/

27. Monteiro WM, Magalhães LKC, de Sá ARN, Gomes ML, Toledo MJ de O, Borges L, et al. Trypanosoma cruzi IV causing outbreaks of acute Chagas disease and infections by different haplotypes in the Western Brazilian Amazonia. PloS One. 2012;7(7):e41284.

28. Kaufer A, Barratt J, Stark D, Ellis J. The complete coding region of the maxicircle as a superior phylogenetic marker for exploring evolutionary relationships between members of the Leishmaniinae. Infect Genet Evol J Mol Epidemiol Evol Genet Infect Dis. 2019;70:90-100.

29. Leon W, Frasch AC, Hoeijmakers JH, Fase-Fowler F, Borst P, Brunel F, et al. Maxi-circles and minicircles in kinetoplast DNA from trypanosoma cruzi. Biochim Biophys Acta. 1980 Apr 30;607(2):22131.

30. Sahyoun AH, Bernt M, Stadler PF, Tout K. GC skew and mitochondrial origins of replication. Mitochondrion. 2014 Jul;17:56-66.

31. Saito S, Tamura K, Aotsuka T. Replication Origin of Mitochondrial DNA in Insects. Genetics. 2005 Dec;171(4):1695-705.

32. Carpenter LR, Englund PT. Kinetoplast maxicircle DNA replication in Crithidia fasciculata and Trypanosoma brucei. Mol Cell Biol. 1995 Dec;15(12):6794-803.

33. Arunkumar KP, Nagaraju J. Unusually Long Palindromes Are Abundant in Mitochondrial Control Regions of Insects and Nematodes. PLoS ONE [Internet]. 2006 Dec 20 [cited 2020 Dec 8];1(1). Available from: https://www.ncbi.nlm.nih.gov/pmc/articles/PMC1762429/

34. Lavi B, Levy Karin E, Pupko T, Hazkani-Covo E. The Prevalence and Evolutionary Conservation of Inverted Repeats in Proteobacteria. Genome Biol Evol. 2018 01;10(3):918-27.

35. Brázda V, Lýsek J, Bartas M, Fojta M. Complex Analyses of Short Inverted Repeats in All Sequenced Chloroplast DNAs [Internet]. Vol. 2018, BioMed Research International. Hindawi; 2018 
[cited 2020 Dec 8]. p. e1097018. Available from:

https://www.hindawi.com/journals/bmri/2018/1097018/

36. Brázda V, Laister RC, Jagelská EB, Arrowsmith C. Cruciform structures are a common DNA feature important for regulating biological processes. BMC Mol Biol. 2011 Aug 5;12(1):33.

37. Shapiro TA. Kinetoplast DNA maxicircles: networks within networks. Proc Natl Acad Sci U S A. 1993 Aug 15;90(16):7809-13.

38. Greif G, Rodriguez M, Bontempi I, Robello C, Alvarez-Valin F. Different kinetoplast degradation patterns in American Trypanosoma vivax strains: Multiple independent origins or fast evolution? Genomics. 2021 Mar;113(2):843-53.

39. Baptista CS, Vêncio RZN, Abdala S, Carranza JC, Westenberger SJ, Silva MN, et al. Differential transcription profiles in Trypanosoma cruzi associated with clinical forms of Chagas disease: Maxicircle NADH dehydrogenase subunit 7 gene truncation in asymptomatic patient isolates. Mol Biochem Parasitol. 2006 Dec;150(2):236-48.

40. Opperdoes FR, Michels PAM. Complex I of Trypanosomatidae: does it exist? Trends Parasitol. 2008 Jul;24(7):310-7.

41. Menna-Barreto RFS, de Castro SL. The double-edged sword in pathogenic trypanosomatids: the pivotal role of mitochondria in oxidative stress and bioenergetics. BioMed Res Int. 2014;2014:614014.

42. Denicola-Seoane A, Rubbo H, Prodanov E, Turrens JF. Succinate-dependent metabolism in Trypanosoma cruzi epimastigotes. Mol Biochem Parasitol. 1992 Aug;54(1):43-50.

43. Thomas S, Martinez LLIT, Westenberger SJ, Sturm NR. A population study of the minicircles in Trypanosoma cruzi: predicting guide RNAs in the absence of empirical RNA editing. BMC Genomics. 2007 May 24;8:133.

44. Blum B, Bakalara N, Simpson L. A model for RNA editing in kinetoplastid mitochondria: "guide" RNA molecules transcribed from maxicircle DNA provide the edited information. Cell. 1990 Jan 26;60(2):189-98.

45. van der Spek H, Arts GJ, Zwaal RR, van den Burg J, Sloof P, Benne R. Conserved genes encode guide RNAs in mitochondria of Crithidia fasciculata. EMBO J. 1991 May;10(5):1217-24.

46. Clement SL, Mingler MK, Koslowsky DJ. An intragenic guide RNA location suggests a complex mechanism for mitochondrial gene expression in Trypanosoma brucei. Eukaryot Cell. 2004 Aug;3(4):862-9.

47. Lewis MD, Llewellyn MS, Yeo M, Acosta N, Gaunt MW, Miles MA. Recent, Independent and Anthropogenic Origins of Trypanosoma cruzi Hybrids. PLoS Negl Trop Dis. 2011 Oct 11;5(10):e1363.

48. Tomasini N, Diosque P. Evolution of Trypanosoma cruzi: clarifying hybridisations, mitochondrial introgressions and phylogenetic relationships between major lineages. Mem Inst Oswaldo Cruz. 2015 May;110(3):403-13.

49. Tomasini N. Introgression of the Kinetoplast DNA: An Unusual Evolutionary Journey in Trypanosoma cruzi. Curr Genomics. 2018 Feb;19(2):133-9.

50. Messenger LA, Llewellyn MS, Bhattacharyya T, Franzén O, Lewis MD, Ramírez JD, et al. Multiple mitochondrial introgression events and heteroplasmy in trypanosoma cruzi revealed by maxicircle MLST and next generation sequencing. PLoS Negl Trop Dis. 2012;6(4):e1584.

51. Díaz-Viraqué F, Pita S, Greif G, de Souza R de CM, Iraola G, Robello C. Nanopore Sequencing Significantly Improves Genome Assembly of the Protozoan Parasite Trypanosoma cruzi. Genome Biol Evol. 2019 Jun 20;11(7):1952-7.

52. Quick J, Grubaugh ND, Pullan ST, Claro IM, Smith AD, Gangavarapu K, et al. Multiplex PCR method for MinION and Illumina sequencing of Zika and other virus genomes directly from clinical samples. Nat Protoc. 2017 Jun;12(6):1261-76.

53. Pita S, Díaz-Viraqué F, Iraola G, Robello C. The Tritryps Comparative Repeatome: Insights on Repetitive Element Evolution in Trypanosomatid Pathogens. Genome Biol Evol. 2019 Feb $1 ; 11(2): 546-51$. 
54. Berná L, Rodriguez M, Chiribao ML, Parodi-Talice A, Pita S, Rijo G, et al. Expanding an expanded genome: long-read sequencing of Trypanosoma cruzi. Microb Genomics. 2018;4(5).

55. Koren S, Schatz MC, Walenz BP, Martin J, Howard JT, Ganapathy G, et al. Hybrid error correction and de novo assembly of single-molecule sequencing reads. Nat Biotechnol. 2012 Jul 1;30(7):693700.

56. Li H, Durbin R. Fast and accurate short read alignment with Burrows-Wheeler transform. Bioinforma Oxf Engl. 2009 Jul 15;25(14):1754-60.

57. Li H, Handsaker B, Wysoker A, Fennell T, Ruan J, Homer N, et al. The Sequence Alignment/Map format and SAMtools. Bioinforma Oxf Engl. 2009 Aug 15;25(16):2078-9.

58. Walker BJ, Abeel T, Shea T, Priest M, Abouelliel A, Sakthikumar S, et al. Pilon: an integrated tool for comprehensive microbial variant detection and genome assembly improvement. PloS One. 2014;9(11):e112963.

59. Camacho C, Coulouris G, Avagyan V, Ma N, Papadopoulos J, Bealer K, et al. BLAST+: architecture and applications. BMC Bioinformatics. 2009 Dec 15;10:421.

60. Quinlan AR, Hall IM. BEDTools: a flexible suite of utilities for comparing genomic features. Bioinforma Oxf Engl. 2010 Mar 15;26(6):841-2.

61. Bankevich A, Nurk S, Antipov D, Gurevich AA, Dvorkin M, Kulikov AS, et al. SPAdes: a new genome assembly algorithm and its applications to single-cell sequencing. J Comput Biol J Comput Mol Cell Biol. 2012 May;19(5):455-77.

62. Li H. Minimap2: pairwise alignment for nucleotide sequences. Bioinforma Oxf Engl. 2018 Sep 15;34(18):3094-100.

63. R Development Core Team. R: a language and environment for statistical computing Version 2.0.1. R Foundation for Statistical Computing: Vienna, Austria; 2004.

64. Robinson JT, Thorvaldsdóttir H, Winckler W, Guttman M, Lander ES, Getz G, et al. Integrative genomics viewer. Nat Biotechnol. 2011 Jan;29(1):24-6.

65. Carver TJ, Rutherford KM, Berriman M, Rajandream MA, Barrell BG, Parkhill J. ACT: the Artemis Comparison Tool. Bioinforma Oxf Engl. 2005 Aug;21(16):3422-3.

66. Krzywinski MI, Schein JE, Birol I, Connors J, Gascoyne R, Horsman D, et al. Circos: An information aesthetic for comparative genomics. Genome Res [Internet]. 2009 Jun 18 [cited 2018 Jan 12]; Available from: http://genome.cshlp.org/content/early/2009/06/15/gr.092759.109

67. Noé L, Kucherov G. YASS: enhancing the sensitivity of DNA similarity search. Nucleic Acids Res. 2005 Jul 1;33(suppl_2):W540-3.

68. Katoh K, Standley DM. MAFFT multiple sequence alignment software version 7: improvements in performance and usability. Mol Biol Evol. 2013 Apr;30(4):772-80.

69. Waterhouse AM, Procter JB, Martin DMA, Clamp M, Barton GJ. Jalview Version 2--a multiple sequence alignment editor and analysis workbench. Bioinforma Oxf Engl. 2009 May 1;25(9):118991.

70. Capella-Gutiérrez S, Silla-Martínez JM, Gabaldón T. trimAl: a tool for automated alignment trimming in large-scale phylogenetic analyses. Bioinforma Oxf Engl. 2009 Aug 1;25(15):1972-3.

71. Chernomor O, von Haeseler A, Minh BQ. Terrace Aware Data Structure for Phylogenomic Inference from Supermatrices. Syst Biol. 2016 Nov;65(6):997-1008.

72. Enright AJ, Van Dongen S, Ouzounis CA. An efficient algorithm for large-scale detection of protein families. Nucleic Acids Res. 2002 Apr 1;30(7):1575-84.

73. Stamatakis A. RAxML version 8: a tool for phylogenetic analysis and post-analysis of large phylogenies. Bioinforma Oxf Engl. 2014 May 1;30(9):1312-3.

74. Keane TM, Creevey CJ, Pentony MM, Naughton TJ, Mclnerney JO. Assessment of methods for amino acid matrix selection and their use on empirical data shows that ad hoc assumptions for choice of matrix are not justified. BMC Evol Biol. 2006;6:29.

75. Lefort V, Longueville J-E, Gascuel O. SMS: Smart Model Selection in PhyML. Mol Biol Evol. 2017 Sep 1;34(9):2422-4.

76. Yu G. Using ggtree to Visualize Data on Tree-Like Structures. Curr Protoc Bioinforma. 2020 
bioRxiv preprint doi: https://doi.org/10.1101/2021.05.11.443566; this version posted May 11, 2021. The copyright holder for this preprint (which was not certified by peer review) is the author/funder, who has granted bioRxiv a license to display the preprint in perpetuity. It is made available under aCC-BY 4.0 International license.

\section{Mar;69(1):e96.}




\section{Figure Captions:}

Figure 1. Architecture of T. cruzi maxicircle. Schematic representation of TcDm28c maxicircle.

Repetitive regions are denoted by internal blast hits inside the circle (blue and light blue). The GC-skew (windows size $100 \mathrm{bp}$ ) are represented in violet (positive) and pink (negative). The GC content (window size $100 \mathrm{bp}$ ) is represented in magenta. The localization of all annotated genes are shown in the outer circle indicating their coding direction (outer + strand, inner - strand).

Figure 2. Structure conservation among T. cruzi maxicircles. A. Schematic representation of TcDm28c maxicircle including: coding region, AT-rich, short repeat region and long repeat region. ATskew and GC-skew are represented in violet and pink respectively. B. Representation of coding region from the six DTU assemblies. Genes are indicated in blue (positive strand), orange (negative strand) or gray (ribosomal genes). Deletions are indicated with red lines, and insertions with green lines. C. Zoom of insertion in TcBolFc10A (see text). D. Conservation of structure of long repeat regions among DTU's showing the $39 \mathrm{bp}$ palindromic sequence.

Figure 3. Dotplot of maxicircles assemblies. Dotplot visualizations by Yass (67) of self-self maxicircle of the six DTUs. Three main classes of maxicircle could be observed (green, blue and orange squares).

Figure 4. Maxicircle phylogeny. A. Matrix of all-against-all uncorrected p-distance . B. Phylogenetic maximum likelihood tree, unrooted visualization (Clades A, B and C are indicated by circles).

Figure 5. Mitochondrial vs Nuclear phylogenies. A. Nuclear phylogenetic maximum likelihood tree using 85 single-copy genes of 11 strains and T. cruzi marinkellei as outgroup. B. 
Mitochondrial (coding region) phylogenetic maximum likelihood tree corresponding to the same 12 strains. Nodes with bootstrap value higher than 0.9 are depicted with a black dot on the node.

Figure 6. Evolutionary relationships in the Trypanosoma cruzi complex. T. cruzi is composed by two main groups 1 and 2, which does not correspond to the original I and II groups. Group 1 is divided in clades A, B and D, and group 2 contains clade C. Lower cases indicate the maxicircle variant $(a, b$, and $c)$, and $B C$ refers to hybrid strains 


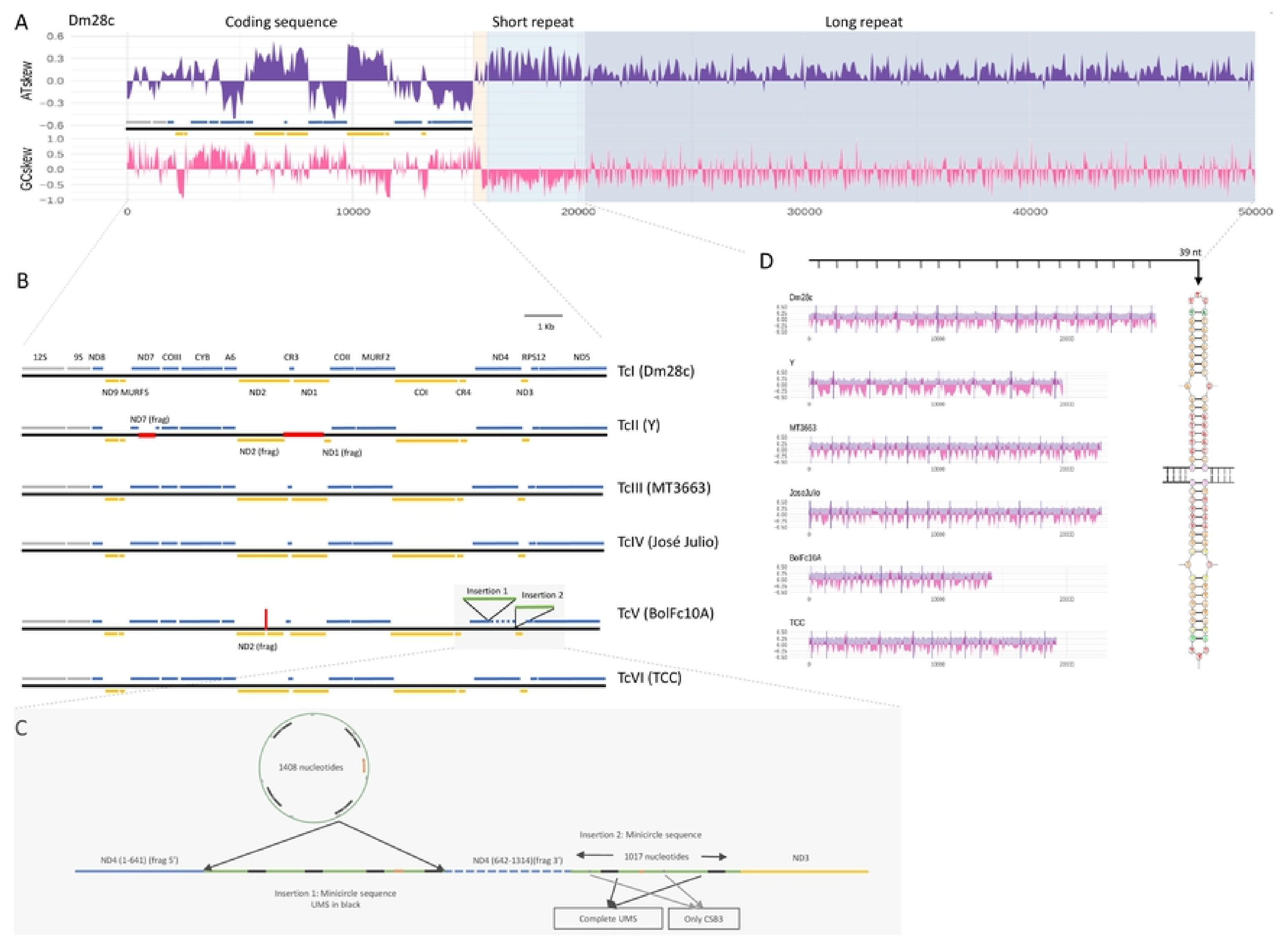

Figure 2 


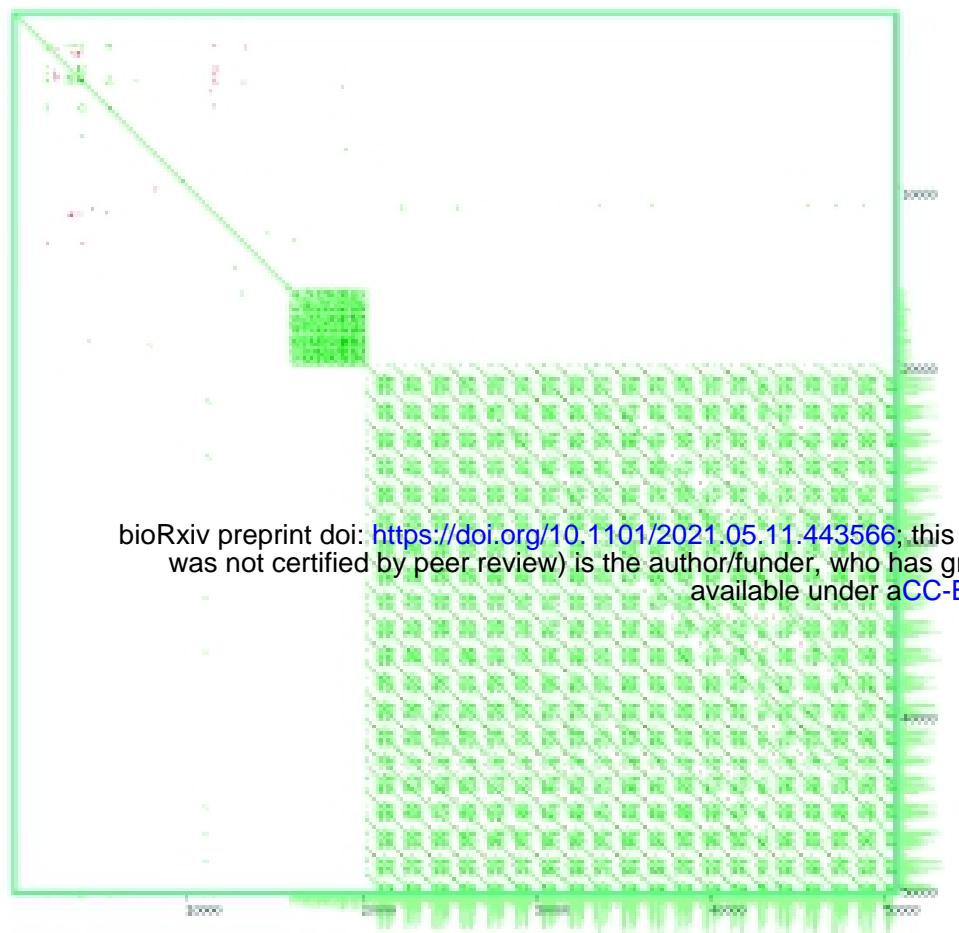

\section{MT3663 (TclII)}

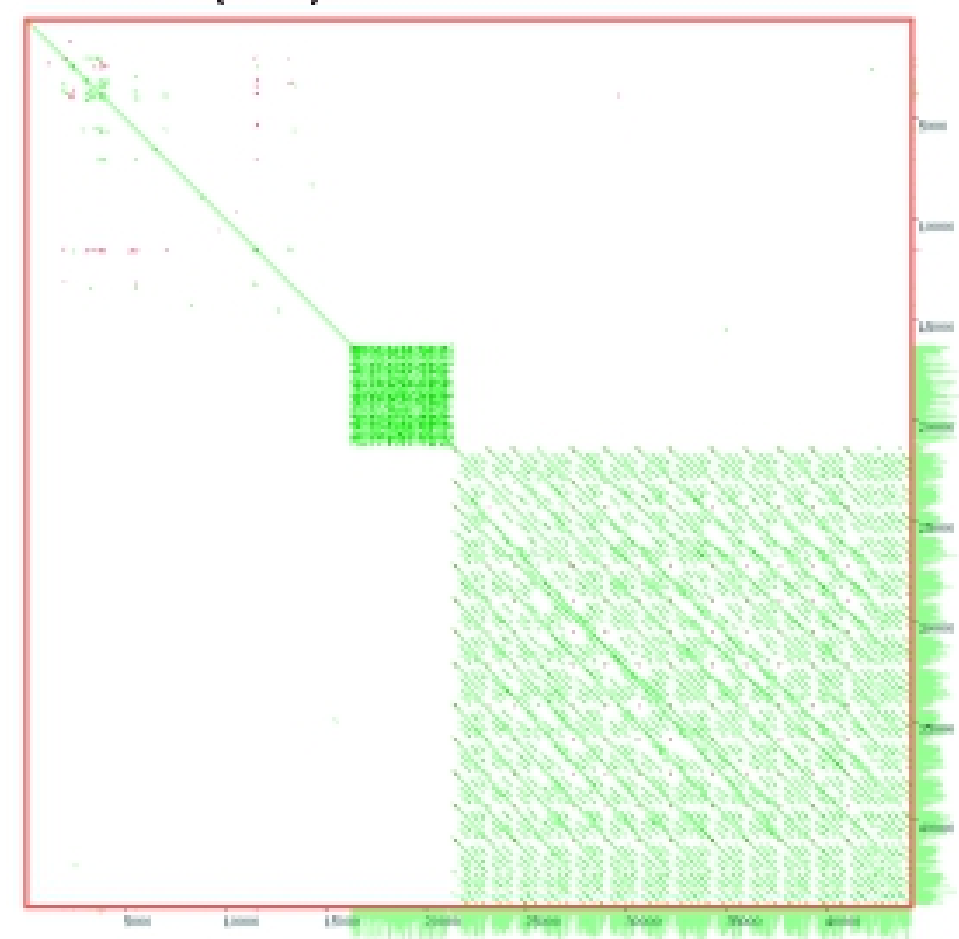

\section{BolFc10A (TcV)}

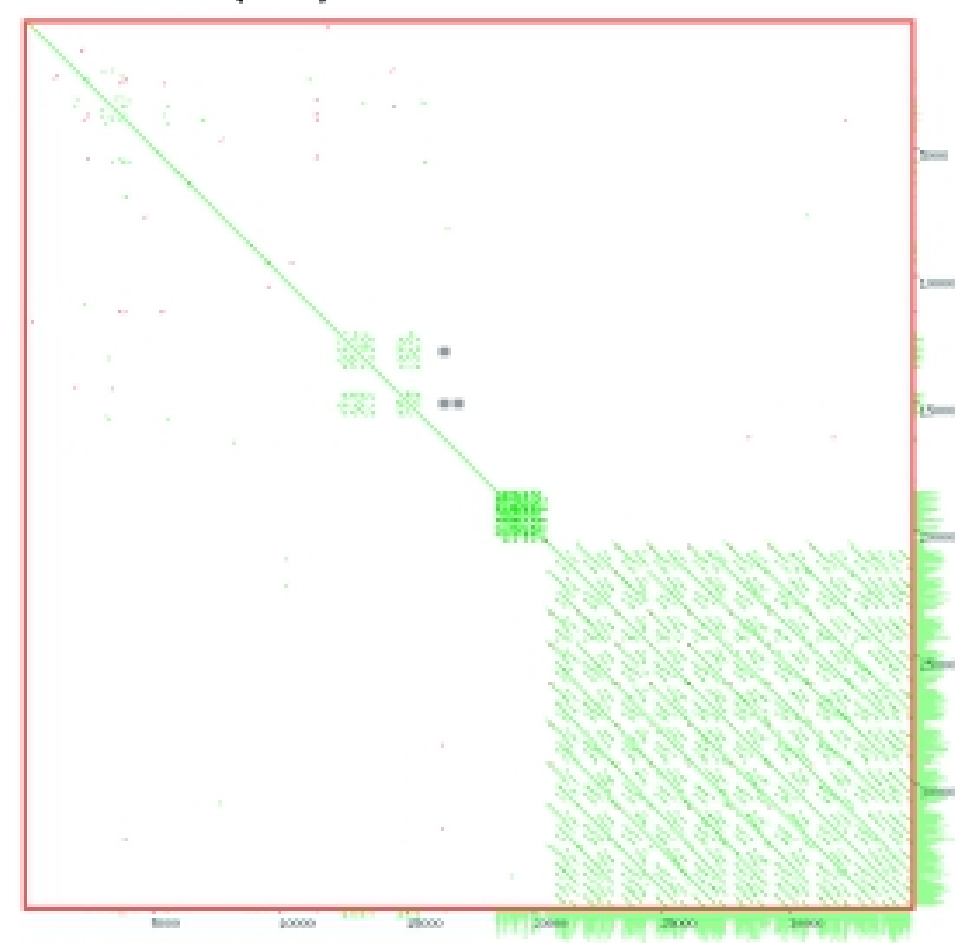

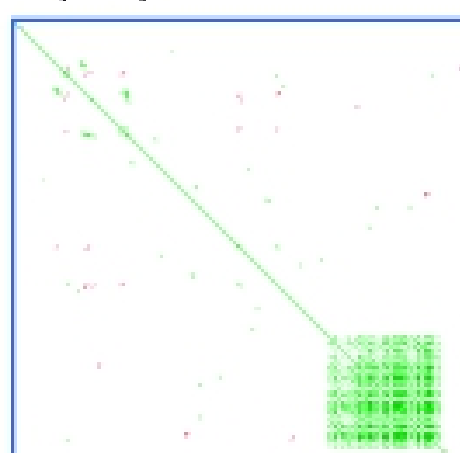

is version posted May 11, 2021. The copyright holder for this preprint (which bioRxiv a license to display the preprint in perpetuity. It is made International license.

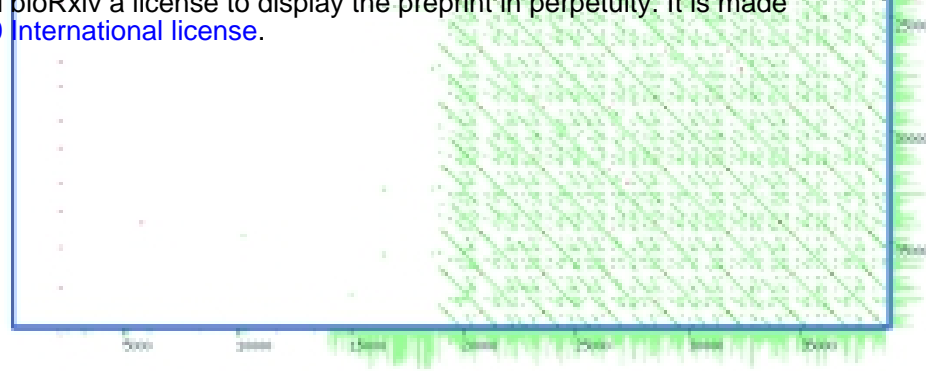

\section{JoseJulio (TcIV)}

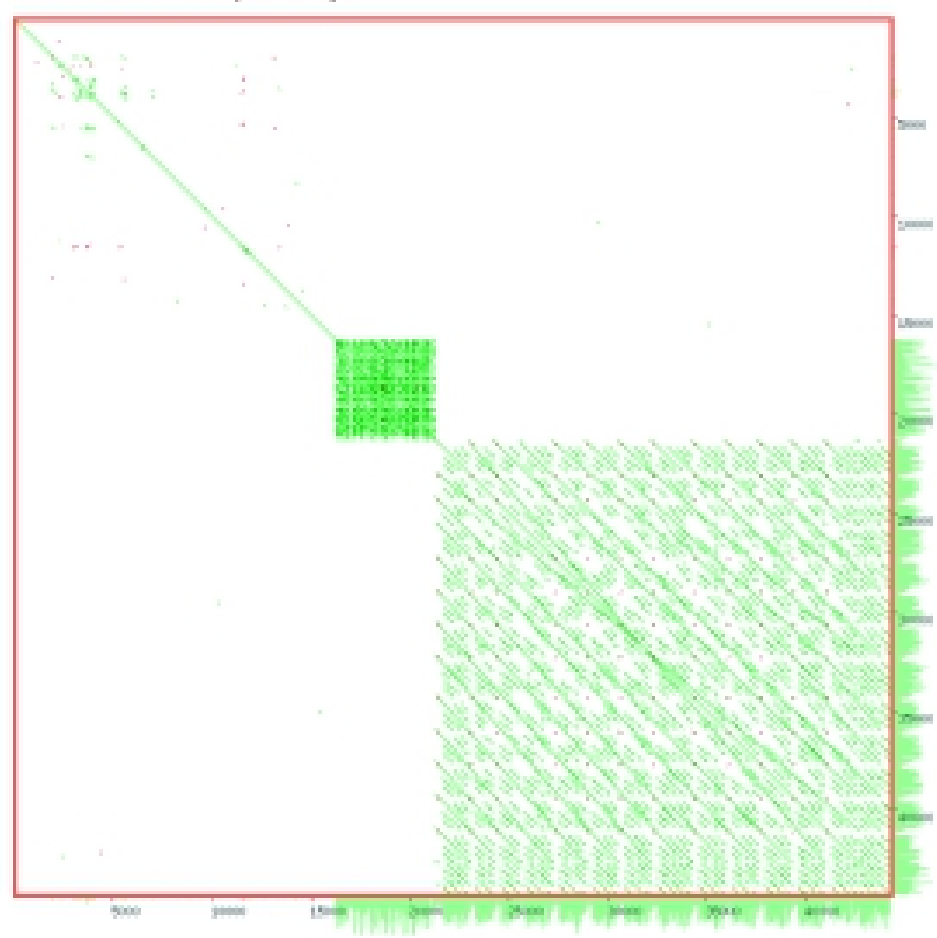

\section{$\mathrm{TCC}(\mathrm{TcVl})$}

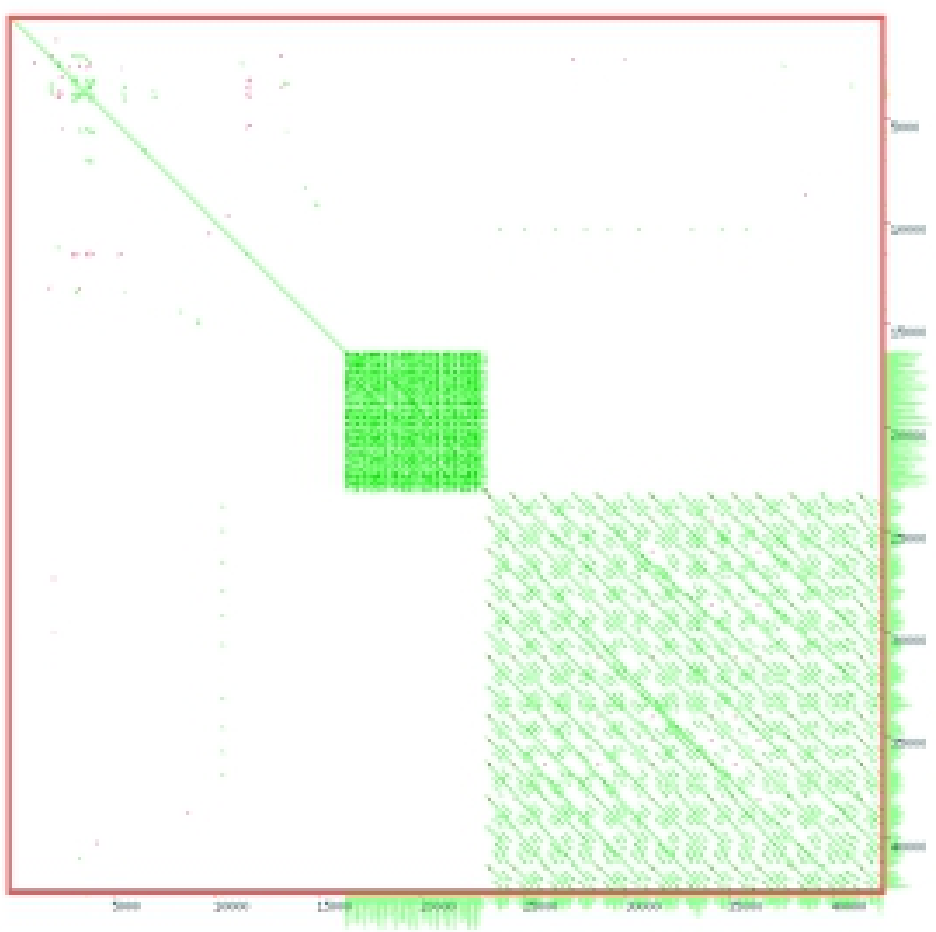

Figure 3 


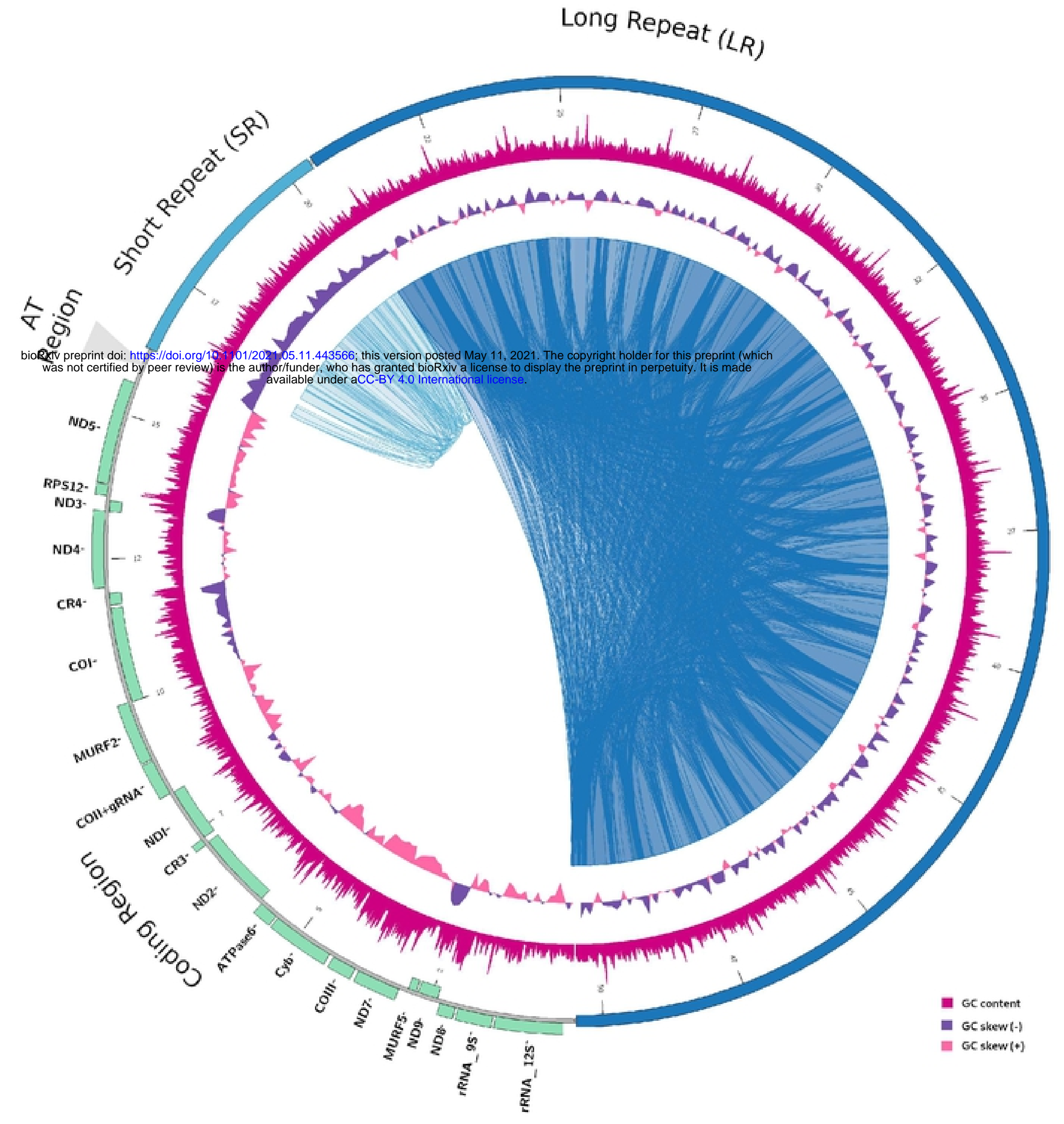

Figure 1 
A

Distances

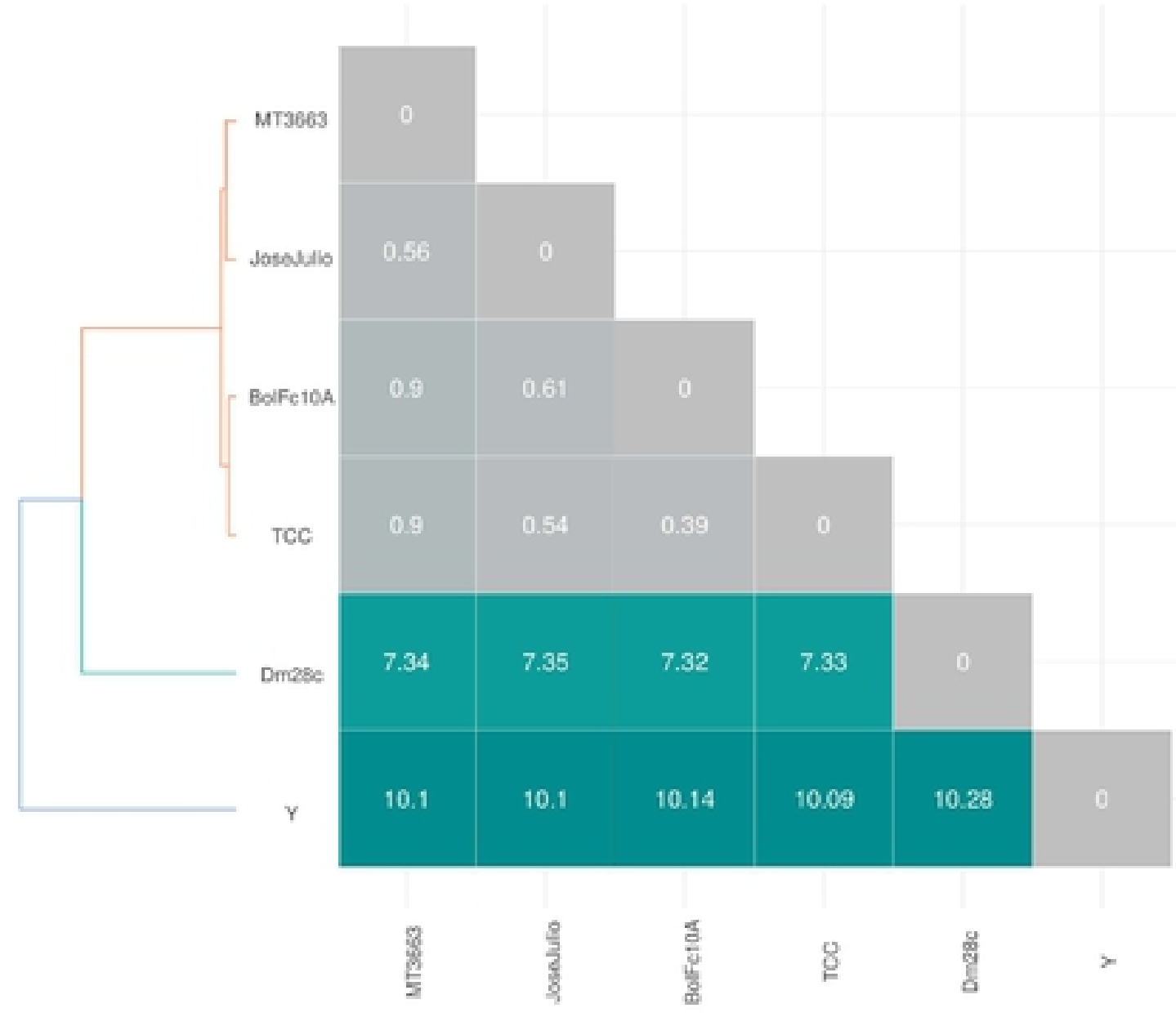

B

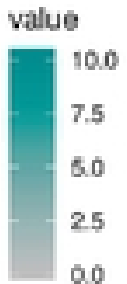

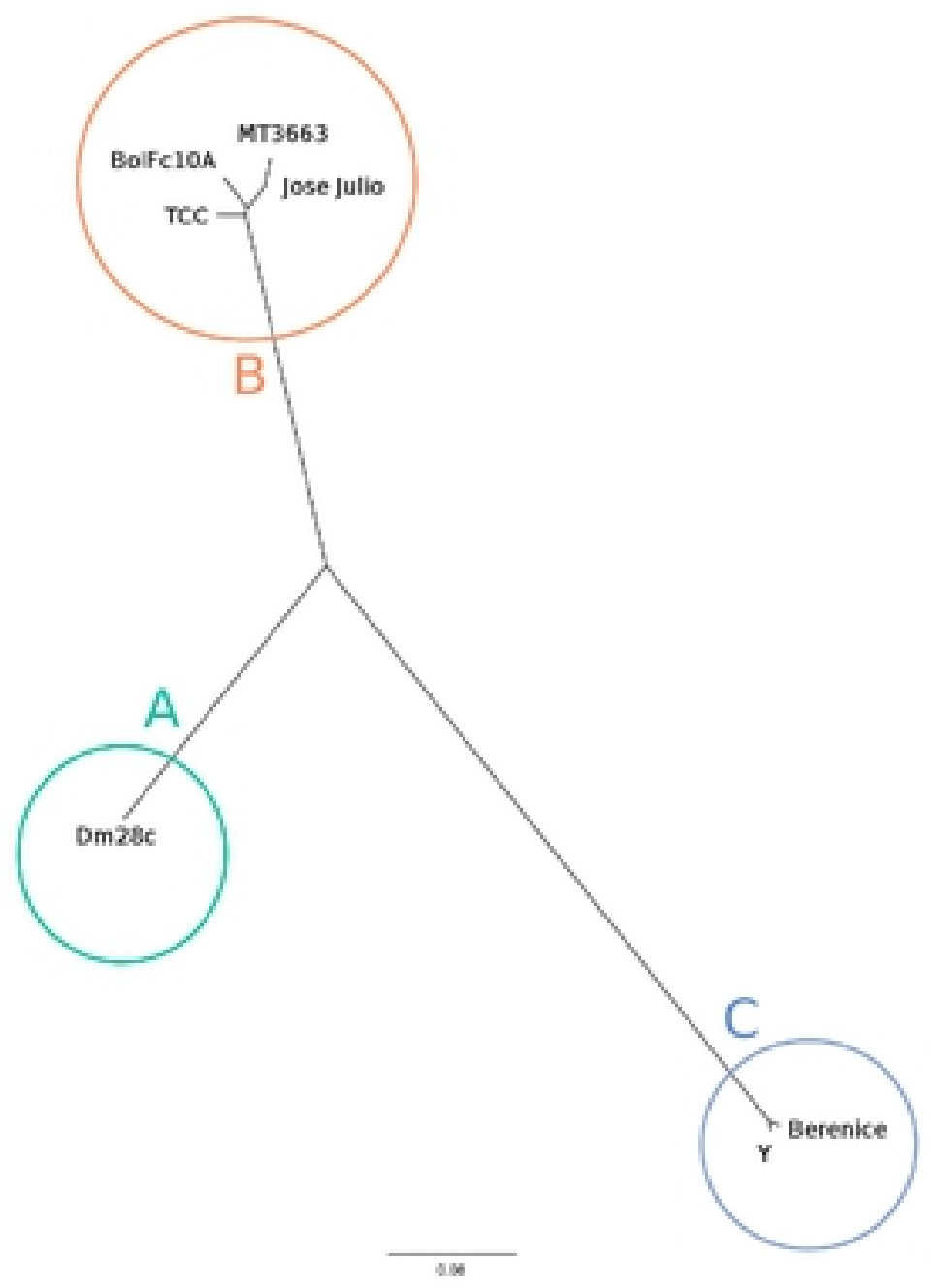

Figure 4 

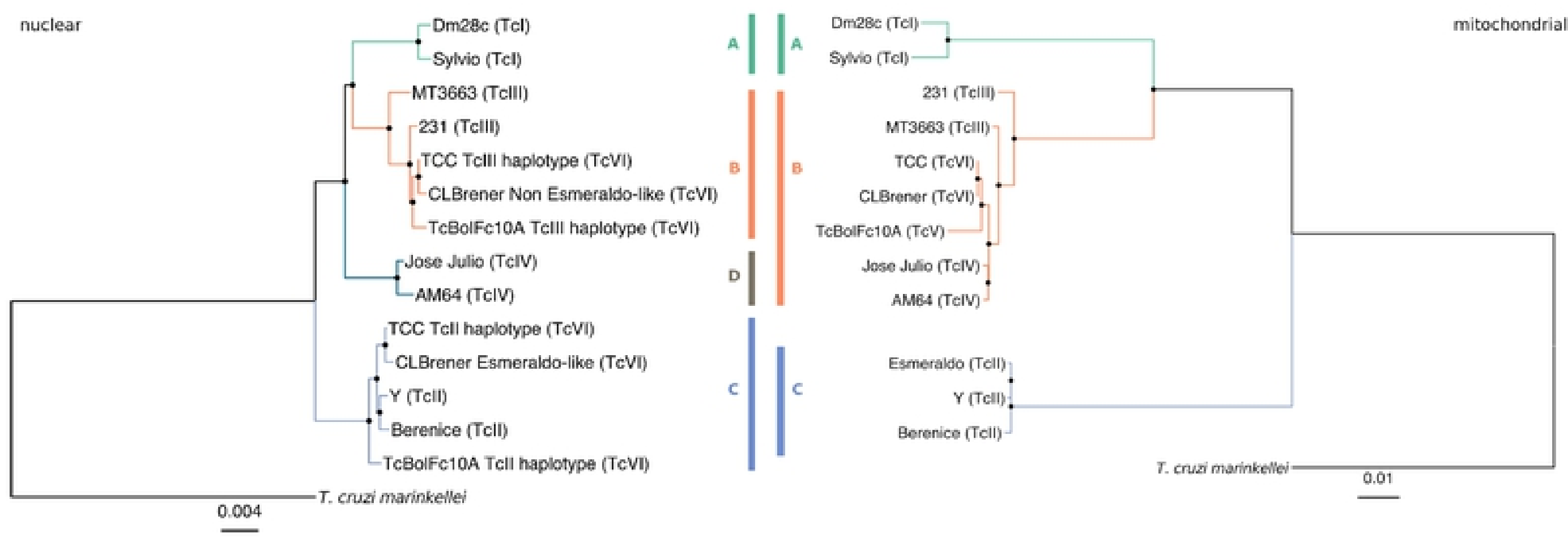

Figure 5 